\title{
Letters
}

Website: www.bmj.com

Email: letters@bmj.com

\section{Trust wants help in formulating system to recognise performance of salaried GPs}

EDITOR-General practitioners (academic and non-academic) are still excluded from the merit award arrangements for consultants. We are therefore asking readers to help us formulate a system to recognise progress and performance for salaried general practitioners in our trust.

We currently employ several general practitioners on the NHS consultant salary scale. They take part in the discretionary points system, but we would like now to develop detailed proposals by which they could progress through enhanced payments-wholly funded by the trustagainst meritorious criteria, which would be widely recognised and acknowledged. This would give them similar opportunities for recognition to those enjoyed by hospital consultant colleagues eligible for B or A merit awards.

We want to determine criteria that emphasise direct clinical care, learning and teaching, research and the development of primary care, and the quality of care provided by the trust. Help with identifying the sorts of skills, behaviours, and competencies that would mark out clinicians who are above the

\section{Advice to authors \\ We prefer to receive all responses electronically, sent either directly to our website or to the editorial office as email or on a disk. Processing your letter will be delayed unless it arrives in an electronic form. \\ We are now posting all direct submissions to our website within 24 hours of receipt and our intention is to post all other electronic submissions there as well. All responses will be eligible for publication in the paper journal. \\ Responses should be under 400 words and relate to articles published in the preceding month. They should include $\leqslant 5$ references, in the Vancouver style, including one to the BMJ article to which they relate. We welcome illustrations. \\ Please supply each author's current appointment and full address, and a phone or fax number or email address for the corresponding author. We ask authors to declare any competing interest. Please send a stamped addressed envelope if you would like to know whether your letter has been accepted or rejected. \\ Letters will be edited and may be shortened. \\ www.bmj.com \\ letters@bmj.com}

norm would enable the trust to continue to deliver a high standard of care for its patients through recognising clinical and other excellence across all specialties.

Currently we insist on membership of the Royal College of General Practitioners as the entry grade to the consultant salary scale for our general practitioners. Fellowship of the college by assessment seems a robust and vigorous test of clinical ability that could be used to move a successful practitioner to the maximum of the discretionary point scale. A further criterion might be contributions to teaching, publications, a research record, a regional or local managerial position, or perhaps a senior position in the BMA or the royal college either locally

An important national role that the trust might wish to support might warrant a yet higher reward in terms of salary. Such a position might be being editor of a major journal; taking a senior role in the Royal College of General Practitioners; holding an office in the BMA or General Practitioners Committee; or holding a major position on other national bodies such as the National Institute for Clinical Excellence. Holding any such positions at international level could result in an even higher reward.

We would be grateful for help in determining the criteria and would appreciate a reply either direct to us or through the $B M J$ 's letter columns. Anyone who wishes to see a final copy of our determination can of course do so.

Sally Irvine chair

Sirvine@ncht.northy.nhs.uk

Lionel Joyce chief executive

Mike Barnes director of clinical governance Newcastle City Health NHS Trust, Newcastle General Hospital, Newcastle upon Tyne NE4 6BE

\section{Preventing injuries in children}

Elements of trial's design and analysis might have biased results

Editor-We overwhelmingly believe that trials should be carried out in primary care to assess child health promotion. Kendrick et al report the lack of effectiveness of a package of health injury prevention strategies delivered by health visitors. ${ }^{1}$ Before this lack of effectiveness is accepted, we recommend critical analysis of elements or nationally. of the design and analysis of the trial that might bias results towards the null hypothesis. Further information is needed to enable the generalisability of interventions to be assessed.

Factors possibly leading to bias

- The control group was potentially contaminated by health visitors and parents in geographically close areas.

- Health visitors were selected because of their interest in research into injury prevention; control health visitors may have increased their injury activities in concurrent health promotion initiatives.

- Were other injury prevention activities occurring at the time?

- A high proportion of the intervention group $(22 \%)$ did not receive any intervention.

- It is unclear whether the time sequence of the study was important as primary outcomes were measured both before and after the intervention, Similarly, the effect of the interventions may have increased beyond the time frame of the trial.

- We question the use of the outcome "at least one medically attended injury." If the intervention was successful it was likely to be more effective for high risk children with more than one injury. As children rather than injuries were counted this cannot be estimated.

- Injury attendance types were undifferentiated (for example, poisons, falls, burns, and scalds); they might have shown a subgroup effect.

- Were there differences between the groups in sample characteristics for nonresponders to the secondary follow up?

Information about the interventions

- Was the intervention based on a proved health promotion model or tested with a subset of the target population to determine its appropriateness or face validity in this setting?

- Is there information on the quality or process indicators of the intervention processes?

- Was low cost safety equipment installed effectively, or were parents unable to make use of this offer because of inadequate equipment or skills?

- Was only a single letter sent to parents, or were non-responders followed up?

- Were the practices that did not take part socioeconomically or otherwise different from those that did?

Outcomes

Contrary to what the authors say in the discussion, increased parental confidence in 
responding to injuries may be the most important early indicator of increasing parents' capacity to introduce changes to the home environment and reduce the severity or occurrence of childhood injury in the family over time.

Elizabeth Waters coordinator

Child Public Health Unit, Centre for Community Child Health, University of Melbourne, Australia elizabeth.waters@nuffield.oxford.ac.uk

Patricia Priest Nuffield fellow

Department of Primary Care and Public Health, University of Oxford, Oxford OX3 9DU

Charlie Foster research officer, British Heart Foundation Health Promotion in Primary Care Research Group

Anne Andermann DPhil student, CRC Primary Care Education Research Group

Department of Public Health, University of Oxford, Oxford OX3 7LF

1 Kendrick D, Marsh P, Fielding K, Miller P. Preventing njuries in children: cluster randomised controlled trial in injuries in children: cluster randomised controlle
primary care. BMJ 1999;318:980-3. (10 April.)

\section{Authors' reply}

EDITOR-We must point out that our conclusion was not that the intervention was ineffective. Rather, we concluded that it did not prevent minor injuries but did suggest a possible reduction in more severe injuries; this requires further research.

Contamination was minimised by the fact that we limited the availability of educational materials and low cost equipment to intervention practices, by regular meetings emphasising the importance of the control group continuing usual practice, and by our eliciting details of injury prevention being undertaken. Only activities for child safety week, in which both groups were participating, were reported before the trial.

We recognise that a penetration of $78 \%$ reduced the effectiveness of the intervention, but this figure is considerably higher than the penetration of $30 \%$ for counselling from a doctor in the statewide childhood injury prevention programme. ${ }^{1}$ Penetration is likely to be lower in routine practice, and hence effectiveness may be further reduced. Persistence of the treatment effect beyond the follow up period is possible, as we discussed in the paper.

Primary outcomes were measured from the start of the intervention period. Invitations for the intervention, sent with baseline questionnaires, were intended to encourage uptake, and we thought it appropriate to measure outcomes from this point. At least one medically attended injury was the primary outcome measure, based on the frequency of this outcome and sample size requirements. Repeated injuries were assessed with Poisson regression, as reported, with total number of injuries per child as the dependent variable. As these are relatively uncommon $(8.9 \%$ and $9.7 \%$ of children in the intervention and control groups respectively) a larger sample size would be required to detect differences in this measure. We did not report injuries by type, as such subgroup analyses would have low power.

The safety advice and low cost equipment had been used in five localities in Nottingham, but formal assessment of their acceptability was not undertaken. We did not assess the fitting of equipment, but stair gates did not require holes to be drilled and smoke alarms could be fixed with sticky pads. Instructions for fitting other equipment were provided. Non-responders to the baseline questionnaire were sent two reminders including intervention invitations, and 55\% received at least one intervention. Participating and non-participating practices were similar socioeconomically (Jarman score: study practices, 15.92-38.19; all practices in Nottingham, 22.35-40.48).

Finally, increases in knowledge and confidence in first aid may indicate capacity to make changes to the home, but the relation between such intermediate outcomes and the frequency of injury needs to be shown.

Denise Kendrick senior lecturer

Division of General Practice, University of

Nottingham, Nottingham NG7 2UH

Denise.Kendrick@nottingham.ac.uk

Patricia Marsh research associate

Roundwood Surgery, Mansfield NG18 1RH

Katherine Fielding statistician

Centers for Disease Control and Prevention, Atlanta, Georgia, USA

Paul Miller lecturer in health economics

Trent Institute for Health Services Research,

University of Nottingham, Nottingham NG7 2UH

1 Guyer B, Gallagher SS, Chang BH, Azzara CV, Cupples LA, Colton T. Prevention of childhood injuries: evaluation of the state-wide childhood injury prevention programme (SCIPP). Am J Public Health 1989;79:1521-7.

\section{Sexual health of homosexual men and women}

Universal vaccination against hepatitis A cannot be firmly recommended for homosexual men

EDITOR-In his article on sexual health issues in homosexual men and women Bell has made inaccurate statements concerning viral hepatitis. ${ }^{1}$ Firstly, he states that hepatitis $\mathrm{B}$ in homosexual men is not spread by specific sexual practices. In fact, several studies have linked homosexual transmission to oroanal and genitoanal sex. ${ }^{2}$ Secondly, he states that the Department of Health recommends vaccination against hepatitis A for all homosexual men. In fact, the recommendation is to vaccinate "those whose sexua behaviour is likely to put them at risk."

The Clinical Effectiveness Group of the Medical Society for the Study of Venereal Disease and the Association of Genitourinary Medicine is about to produce guidelines on the management of viral hepatitis, for which I am the main author. These guidelines state that in gay men "universal vaccination cannot be firmly recommended" (unpublished).

Gary Brook consultant physician

Patrick Clements Clinic, Central Middlesex Hospital, London NW10 7NS

1 Bell R. ABC of sexual health. Homosexual men and women. BMJ 1999;318:452-5. (13 February.)

2 Brook MG. Sexual transmission and prevention of the hepatitis viruses A-E and G. Sex Transm Infect 1998;74: 395-8

3 Department of Health. Hepatitis A. In: Salisbury DM, Begg

NT, eds. Immunisation against infectious disease. London: HMSO, 1996:85-94.

\section{Author's reply}

EDITOR-As Brook suggests, it is received wisdom that specific sexual practices increase the risk of hepatitis B among homosexual men. Evidence for this is actually rather sparse. In his own review article Brook cites two sources for this assertion': Keefe's review article, which does not present primary data, ${ }^{2}$ and Schreeder et al's article, which presented data showing that the only sexual activity that was an independent risk factor for acquiring hepatitis B was rectal douching. ${ }^{3}$ Oroanal and genitoanal sex are not significant once the number of partners is allowed for. Other papers have suggested the same: crude data show significance, but after adjustment for number of partners the figures are not significant. I agree that the Department of Health's recommendations for vaccination against hepatitis $\mathrm{A}$ in homosexual men leave room for discussion. It is difficult to comment on a quote from an unpublished document, and I look forward to reading the quote in context and with an explanation for its controversial conclusion.

The rationale for suggesting universal vaccination against hepatitis $\mathrm{A}$ in homosexual men is as follows. The seroprevalence of previous exposure to hepatitis A is low in homosexual men, as in the general population, and they are therefore susceptible. There have been well recorded epidemics of hepatitis A in this group associated with sexual exposure, but they have spilled over to the general population. ${ }^{14}$ Vaccination of the core group-homosexual men-should prevent such epidemics and protect both this group and the general population.

Vaccination is effective and has few side effects. Medically, universal vaccination in this group is desirable. I guess that financial constraint would weaken the argument, but I have not seen a cost benefit analysis of this published.

Robin Bell staff grade physician Jefferiss Wing, St Mary's Hospital, London W2 1NY

1 Brook MG. Sexual transmission and prevention of the hepatitis viruses A-E and G. Sex Transm Infect 1998;74:395-8

2 Keefe EB Clinical approach to viral hepatitis in homosexual men. Med Clin NAm 1986;70:567-86.

3 Schreeder MT, Thompson SE, Hadler SC, Berquist KR, Zaidi A Maynard JE et al. Hepetitis B in homosexualme Zaidi A, Maynard JE, et al. Hepatitis B in homosexual men: prevalence of infection an

4 Chis Dis $1982,146: 7-15.2$ C, Botinger M, Hennanson J, Weitar among homosexual men in Stockholm. Hepatitis A, a special hazard for the male homosexual subpopulation in Sweden. Am J Epidemiol 1982;116:599-607.

\section{The end of the heparin pump?}

\section{Dosage regimens for low molecular weight heparins differ}

EDITOR-Grubb et al's editorial reviewed the use of subcutaneous heparin; the advantages in efficacy and simplicity in the treatment of thromboembolic disease and angina now seem clear. ${ }^{1}$ A potential difficulty, which is clear in the everyday use of these agents, is the differing dosages required. Because the agents are commonly prescribed in a busy on-call setting, calculation errors are also 
Dosage regimens for low molecular weight (LMW) heparins available in United Kingdom for treatment of thromboembolism and unstable angina

\begin{tabular}{lcc} 
& \multicolumn{2}{c}{ LMW heparin } \\
\cline { 2 - 3 } LMW heparin & Thromboembolism & Unstable angina \\
\hline Enoxaparin & $1 \mathrm{mg} / \mathrm{kg} / 12 \mathrm{~h}$ & $1 \mathrm{mg} / \mathrm{kg} / 12 \mathrm{~h}$ \\
\hline Dalteparin & $200 \mathrm{IU} / \mathrm{kg} /$ day & $120 \mathrm{IU} / \mathrm{kg} / 12 \mathrm{~h}$ \\
\hline Tinzaparin & $175 \mathrm{IU} / \mathrm{kg} /$ day & $\mathrm{NA}$ \\
\hline
\end{tabular}

NA=Not applicable.

more likely to occur. Five agents are mentioned, of which three are available in the United Kingdom. The table shows the dosage regimens for these agents.

Other agents with similar indications will probably be licensed. Perhaps it would be useful for regulatory bodies to introduce a uniform system of equivalent doses, similar to that used in insulin prescription.

Mark Lloyd senior registrar

Department of Rheumatology, St Thomas's

Hospital, London SE1 7EH

mark@lloyd6236.freeserve.co.uk

1 Grubb NR, Bloomfield P, Ludlam CA. The end of the heparin pump? BMJ 1998;317:1540-2.

\section{Epidural haematoma may occur after} epidural and spinal regional anaesthesia

EDITOR-In their editorial Grubb et al reviewed the advantages of low molecular weight heparins over unfractionated heparin in a variety of clinical situations and pointed out that they can be used for thromboprophylaxis in certain types of surgery. ${ }^{1}$ They urged caution when considering practical procedures such as arterial sampling and insertion of central venous lines but omitted to highlight the risk of epidural haematoma after epidural and spinal regional anaesthesia or lumbar puncture.

Cases of life threatening expanding haematoma in the spinal canal in patients who are receiving either type of heparin have been reported. ${ }^{2}$ Members of the Food and Drug Administration in the United States have expressed concern about reports they have received on 36 patients who had spinal or epidural haematoma after receiving low molecular weight heparins in association with epidural and spinal anaesthesia. ${ }^{3}$ As a result of these reports the Food and Drug Administration has asked the manufacturers to include a "black box" warning of this potential complication in their product labelling. It has been recommended that, to minimise this complication, epidural and spinal blocks should only be started one hour before low molecular weight heparins or over 12 hours after the last dose. ${ }^{4}$

Christopher C Callander consultant anaesthetist Royal Gwent Hospital, Newport, Gwent NP9 2UB ceverett@gwent.nhs.gov.uk

1 Grubb NR, Bloomfield P, Ludlam CA. The end of the heparin pump? BMJ 1998;317:1540-2.

2 Vandermeulen EP, Van Aken H, Vermylen J. Anticoagulants and spinal-epidural anaesthesia. Anesth Analg 1994;79:1165-77.

3 Wysowski DK, Talaricol L, Bacsanyi J, Botstein P. Spinal and epidural haematoma and low-molecular-weight heparin. N Engl J Med 1998;338:1774-5.

4 Bullingham A Strunin I Prevention of postoperative venous thromboembolism. Br JAnaesth 1995;75:622-30.
Low molecular weight heparins have practical advantages, but clinical advantages are small

EDITOR-Grubb et al identify low molecular weight heparin as a potentially cost effective element in the management of unstable coronary artery disease. ${ }^{1}$ Several small inaccuracies in their editorial may, however, serve to overstate the quality and strength of the evidence base and add to the points made by Jefferson. ${ }^{2}$

Grubb et al suggest that the ESSENCE study shows that enoxaparin is as effective as unfractionated heparin at preventing any of the three major outcomes (death, myocardial infarction, and recurrent angina). ${ }^{3}$ In fact, this was a composite outcome: no significant effect was shown on each of these measures individually. Also, it is wrong to say that the incidence of minor haemorrhagic complications was the same in the two groups in the trial. Altogether $11.9 \%$ of patients taking enoxaparin had minor bleeding complications, compared with $7.2 \%$ taking unfractionated heparin $(\mathrm{P}<0.001)$.

Furthermore, it is wrong to say that the FRIC study ${ }^{4}$ showed that dalteparin prevents death. By day 6 (at the end of the first phase of the study) significantly more deaths had occurred in the dalteparin group than the unfractionated heparin group, although the number of events was small (11 deaths $v 3$ deaths; relative risk 3.37 (95\% confidence interval 1.01 to 11.24$)$ ).

Using low molecular weight heparins has undoubted practical advantages, but the clinical advantages they offer are small. What is not clear is whether the savings that theoretically might be made alongside clinical benefits can be realised in practice, either within cardiac care services or to allow investment in other areas.

Ken Stein consultant in public health medicine North and East Devon Health Authority, Exeter EX1 1QT

Ken.Stein@nedevon-ha.swest.nhs.uk

Tricia Nicholson research assistant

Wessex Institute for Health Research and Development, University of Southampton, Southampton SO16 7PX

1 Grubb NR, Bloomfield P, Ludlam CA. The end of the heparin pump? BMJ 1998;317:1540-2

2 Jefferson $T$. What are the benefits of editorials and non-systematic reviews? BMJ 1999;318:135. (9 January.) 3 Cohen M, Demers C, Gurfinkel EP, Turpie AG, Fromell GJ, Goodman S, et al. A comparison of low-molecular-weigh heparin with unfractionated heparin for unstable coronary artery disease. Eflicacy and Safety of Subcutaneou Enoxaparin in Non- $Q-W a v e$ Corong Houp. N Engl J Med 1997;337:447-52.

Sanz Gm Turpie AG, et al. Comparison of low-molecular-weight heparin with unfractionated heparin acutely and with placebo for 6 weeks in the management of unstable coronary artery disease. Fragmin in unstable coronary artery disease study (FRIC). Circulation 1997;96:61-8.

\section{Author's reply}

EDITOR-There is certainly potential for confusion about doses of low molecular weight heparins, and my colleagues and I appreciate Lloyd's clarification of these. We would emphasise that low molecular weight heparins should be prescribed only for indications for which the agent is proved and licensed, as shown in the table that Lloyd provides. For instance, not all low molecular weight heparins are necessarily effective for unstable angina. Callander's comments in his letter highlight a potentially dangerous complication of low molecular weight heparins in patients undergoing epidural or spinal anaesthesia.

Stein and Nicholson raise some points that require clarification. Firstly, we agree that the ESSENCE trial's primary end point was the composite of death, myocardial infarction, or recurrent angina at 14 day follow up. Enoxaparin plus aspirin was superior to unfractionated heparin plus aspirin with respect to this end point. For each of the individual end points, outcomes were not shown to be superior. Secondly, we wrongly stated that enoxaparin was associated with a similar rate of minor haemorrhagic events in that trial. Mainly as a result of bruising at the injection site, enoxaparin was associated with a significantly higher rate of these events. We apologise for making this clear error. Thirdly, in the FRIC study, the primary outcomes included death after the prolonged treatment phase, not the acute phase. For this time point the death rate was identical in the dalteparin and unfractionated heparin groups $(2 \%)$.

Neil Grubb lecturer in cardiology Department of Cardiology, Royal Infirmary of Edinburgh, Edinburgh EH3 9YW

\section{Number of cases operated on is important in volume-outcome debate for colorectal cancer}

EDITOR-Comber draws a distinction between hospital based registration systems and a population based registry and raises the possibility that we missed cases of color-

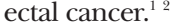

The leaders of both the Northern Ireland cancer register and the colorectal cancer register have shared their data for several years. Those at the colorectal cancer register are aware that their ascertainment focuses on patients having surgical intervention. As our paper indicated, ${ }^{2}$ we focused our analysis on patients who had surgical intervention as this seems to be the most obvious first step in analysing the volumeoutcome debate. We know from the hospital patient administration systems that during 1990-4, 3414 inpatient episodes had a diagnosis of colorectal cancer and an OPCS-IV operation code $^{3}$ of HO4-H20, H30, H20$\mathrm{H} 28$, or H33-H41. The episode count over a period almost certainly overestimates the number of patients having these operations with a diagnosis of colorectal cancer, ${ }^{4}$ and so it is likely that our ascertainment of all those having surgery is at least $92 \%$ and probably higher.

Comber's letter raises an interesting and worthwhile subsidiary question, which we have discussed with the director of the 
Northern Ireland cancer register-namely, is the outcome of patients who do not receive surgery any better or any worse in hospitals with high or low surgical volumes? Our study did not attempt to answer this question.

The quoted incidence of colorectal cancer drawn from the first report of the Northern Ireland cancer register places the province extremely high in the league table of the incidence of colorectal cancer in the United Kingdom. However, the ratio of mortality to incidence for the cancer register is among the lowest in the United Kingdom, and few local clinicians believe that this has much to do with better survival in Northern Ireland. Whereas the standardised mortality ratios for colon cancer for men and women in Northern Ireland are $20 \%$ and $9 \%$ in excess of those in the rest of the United Kingdom, the published age standardised incidence is between $30 \%$ and $40 \%$ in excess of that in England and Wales. The excess for rectal cancer (more than $10 \%$ and 20\% greater than the rates in England and Wales for men and women) is even harder to reconcile when the standardised mortality ratios from the disease are lower than those in the rest of the United Kingdom. Clearly the trends in incidence over time will merit scrutiny.

Frank Kee chair

Department of Public Health Medicine, Queen's

University of Belfast, Belfast BT12 6BJ

f.kee@qub.ac.uk

1 Comber H. Some patients with colorectal cancer may have been missed by Northern ireland registry. $B M$ been missed by No

2 Kee F, Wilson RH, Harper C, Patterson CC, McCallion K, Houston RF, et al. Influence of hospital and clinician workHouston RF, et al. Influence of hospital and clinician work-
load on survival from colorectal cancer: cohort study. BMJ

3 Office of Population Censuses and Surveys. Tabular list of the classification of surgical operations and procedures. 4 th revision. London: HMSO, 1990

4 Clarke A, McKee M. The consultant episode: an unhelpful measure. BMJ 1992;305:1307-8

\section{Role of antioxidant vitamins in prevention of cardiovascular diseases}

\section{Meta-analysis seems to exclude benefit of vitamin $\mathbf{C}$ supplementation}

EDITOR-The first article in the series on evidence based cardiology summarises evidence on the effect of antioxidant vitamins on the risk of cardiovascular disease. ${ }^{1}$ The summary of the trial evidence for vitamin $\mathrm{C}$ supplementation is, however, incomplete, and the authors' interpretation of the available data on antioxidants is too optimistic.

The authors describe Wilson et al's trial of vitamin C, in which 538 patients admitted to an acute geriatric unit were randomised to receive $200 \mathrm{mg}$ of vitamin $\mathrm{C}$ or placebo daily for six months. ${ }^{2}$ We are aware of two further trials of vitamin $\mathrm{C}$ supplementation in Western populations that have reported on mortality from all causes. Burr et al randomised 297 elderly people with low vitamin $\mathrm{C}$ concentrations to receive vitamin

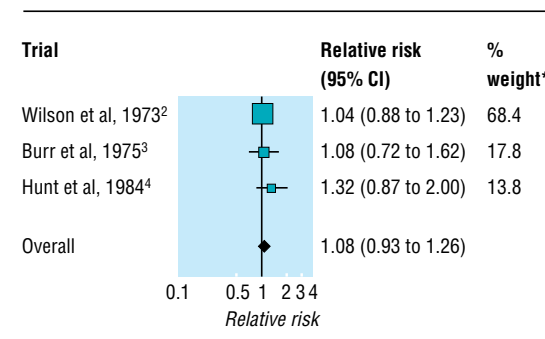

Results of meta-analysis of three trials of vitamin C supplementation in elderly subjects, showing mortality from all causes. *Amount that each study contributes to pooled estimate of effect of vitamin C supplements.

C (150 mg a day for 12 weeks and $50 \mathrm{mg}$ a day thereafter) or placebo for two years." Hunt et al randomised 199 elderly patients to receive $200 \mathrm{mg}$ of vitamin $\mathrm{C}$ or placebo daily for six months.

We performed a meta-analysis of all three trials using a fixed effects model (figure). Even though the three trials were small and relatively short, the combined results seem to exclude any substantial early benefit of vitamin $\mathrm{C}$ supplementation. The overall relative risk shows an increase in mortality of $8 \%$, with the $95 \%$ confidence interval ranging from a 7\% reduction to a $26 \%$ increase in mortality $(\mathrm{P}=0.29)$. An earlier meta-analysis of the $\beta$ carotene trials also showed a moderate adverse effect, which was significant $(\mathrm{P}=0.005)$.

Lonn and Yusuf argue that the strong biological rationale and observational epidemiological data relating antioxidants to lower cardiovascular risk justify ongoing trials. We believe that the disappointing results for vitamin $\mathrm{C}$ and $\beta$ carotene should lead us to re-evaluate critically the status of the antioxidant hypothesis and to consider confounding as an alternative explanation for the lower cardiovascular risk observed in epidemiological studies. ${ }^{5}$

The ongoing trials of antioxidant vitamins should continue because we need to know whether vitamin supplementswidely used in preparations sold over the counter-produce any benefit or are in fact harmful. When potentially protective dietary constituents are identified in the future it may be more sensible to undertake trials of foods that are rich sources of these constituents rather than supplementation trials.

Andy Ness senior lecturer in epidemiology Andy.Ness@bris.ac.uk

Matthias Egger senior lecturer in epidemiology and public health medicine

George Davey Smith professor of clinical epidemiology

Department of Social Medicine, Bristol BS6 7DP

1 Lonn E, Yusuf S. Emerging approaches in preventing cardiovascular disease. BMJ 1999;318:1337-41. (15 Mav.)

2 Wilson TS, Datta SB, Murrell JS, Andrews CT. Relation of vitamin $\mathrm{C}$ levels to mortality in a geriatric hospital: a study of the effect of vitamin C administration. Age Ageing 1973;2:163-70.

3 Burr ML, Hurley RJ, Sweetnam PM. Vitamin C supplementation of old people with low blood levels. Gerontol Clin 1975; 17:296-43.
4 Hunt C, Chakkravorty NK, Annan G. The clinical and biochemical effects of vitamin $\mathrm{C}$ supplementation in short-stay hospitalized geriatric patients. Int J Vit Nutr Res 1984;54:65-74

5 Egger M, Schneider M, Davey Smith G. Spurious precision? Meta-analysis of observational studies. BMJ 1998;316:140-5.

\section{Authors' reply}

EDitor-We do not believe that there is any major disagreement between our views and those expressed in Ness et al's letter. The two additional negative trials of vitamin $\mathrm{C}$ that they mention were quite small clinical trials, and overall we believe that the clinical trials data for vitamin $\mathrm{C}$ remain inconclusive. As we stated in our review article, we found the observational data for vitamin $\mathrm{C}$ to be not particularly supportive of a role for the vitamin in reducing cardiovascular risk. The use of vitamin C supplements (in isolation) in cardiovascular prevention is therefore not promising.

The epidemiological data for $B$ carotene and especially for vitamin $\mathrm{E}$ are more promising. We agree with Ness et al that the clinical trials of $\beta$ carotene, although performed only in men and in primary prevention settings, have effectively shown the lack of efficacy of supplementation with $B$ carotene. As the authors are aware, interesting epidemiological data exist for other carotenoids and for diets rich in fruit and vegetables with high contents of carotenoids as potential protective factors in cardiovascular prevention. Further clinical trials data are needed for vitamin $\mathrm{E}$.

We do not believe that our view is too optimistic. As we clearly stated in our paper, we agree that results of clinical trials do not at present support the use of antioxidant vitamin supplements in cardiovascular prevention. We do, however, believe-as do many other investigators around the worldthat clinical trials are warranted to clarify this issue, particularly regarding vitamin $\mathrm{E}$.

Several large clinical trials are ongoing or have been completed recently. The GISSI (Gruppo Italiano per lo Studio della Streptochinasi nell'Infarto Miocardio) prevention study, conducted in 12000 patients after myocardial infarction, reported a modest, non-significant $4.7 \%$ reduction in risk for the end point cluster of total mortality, non-fatal myocardial infarction, and cerebrovascular accident. These data further put into question the results of other trials and experimental basic research studies and epidemiological investigations.

We believe that the medical community should await the results of the other ongoing trials of vitamin E, including the study coordinated by our centre. This is the heart outcomes prevention evaluation trial, in 9541 patients, which will provide more conclusive results regarding a potential role for vitamin $\mathrm{E}$ in cardiovascular prevention.

Eva Lonn associate professor of medicine lonnem@fhs.mcmaster.ca

Salim Yusuf professor of medicine

Division of Cardiology, Hamilton Health Sciences Corporation, General Site, Hamilton, ON L8L 2X2, Canada 


\section{CRASH trial is based on problematic meta-analysis}

EDITOR-Kmietowicz reports the start of the CRASH trial, a multicentre trial of steroids for treating head injury. ${ }^{1}$ The meta-analysis which forms the basis for the trial is a good example of how one small study can potentially expose thousands of patients to unnecessary risk. The dose of steroids used in CRASH (2 g methyl prednisolone over 1 hour followed by $0.39 \mathrm{~g} / \mathrm{h}$ for 48 hours) may cause fluid retention, raised glucose concentrations, immunosuppression, and gastric erosions with gastrointestinal bleeding. These hazards are particularly important in vulnerable and often ventilated head injured patients.

The suggestion of possible benefit from steroids comes from the meta-analysis by Alderson and Roberts published in 1997. ${ }^{2}$ In that meta-analysis the odds ratio for death $(0.91,95 \%$ confidence interval 0.74 to 1.12) is heavily influenced by the small trial by Faupel et al in $1976 .^{3}$ This trial was of poor quality, did not use acceptable randomisation (class B according to Alderson and Roberts), and used discharge outcomes which Alderson and Roberts say may account for "incongruous" results.

If the Faupel trial is removed from the meta-analysis, steroid treatment does not seem to convey benefits. We recalculated the Peto odds ratio without the Faupel study (figure). If the other trials which do not use adequate concealment are also removed, any possible benefit is eliminated, and indeed the Peto odds ratio would indicate that steroids are potentially harmful (figure).

Ethics committees considering the safety of high dose steroid treatment in head injury need to consider the significant risks of these doses and weigh them against the vanishingly small benefits that may accrue.

B Gregson principal research associate

N V Todd consultant anaesthetist, intensive care

D Crawford consultant anaesthetist, intensive care

C J Gerber consultant neurosurgeon

B Fulton consultant neurosurgeon

L Tacconi consultant neurosurgeon

P J Crawford consultant neurosurgeon

R P Sengupta consultant neurosurgeon

Newcastle General Hospital, Acute Services,

Newcastle upon Tyne NE4 6BE

1 Kmietowicz Z. Trial of steroids for treating head injury begins. BMJ 1999;318:1441. (29 May.)

2 Alderson P, Roberts I. Corticosteroids in acute traumatic brain injury: systematic review of randomised controlled trials. $B M J$ 1997;314:1855-9

3 Faupel G, Renlen HJ, Muller D, Schurmann K. Double blind study on the effects of steroids on severe closed head

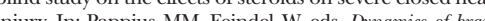
mics of brain edema. Berlin: Springer Verlag. 1976:337-43.

\section{Response to requests for genetic testing is not based on age alone}

EDITOR-Dickenson's article on genetic testing for adult onset disorders in young people raises an important issue, ${ }^{1}$ but her statement that "many clinical genetics units operate a bar at 18 " suggests a lack of familiarity with current practice in clinical genetics and the way it has evolved since genetic test-

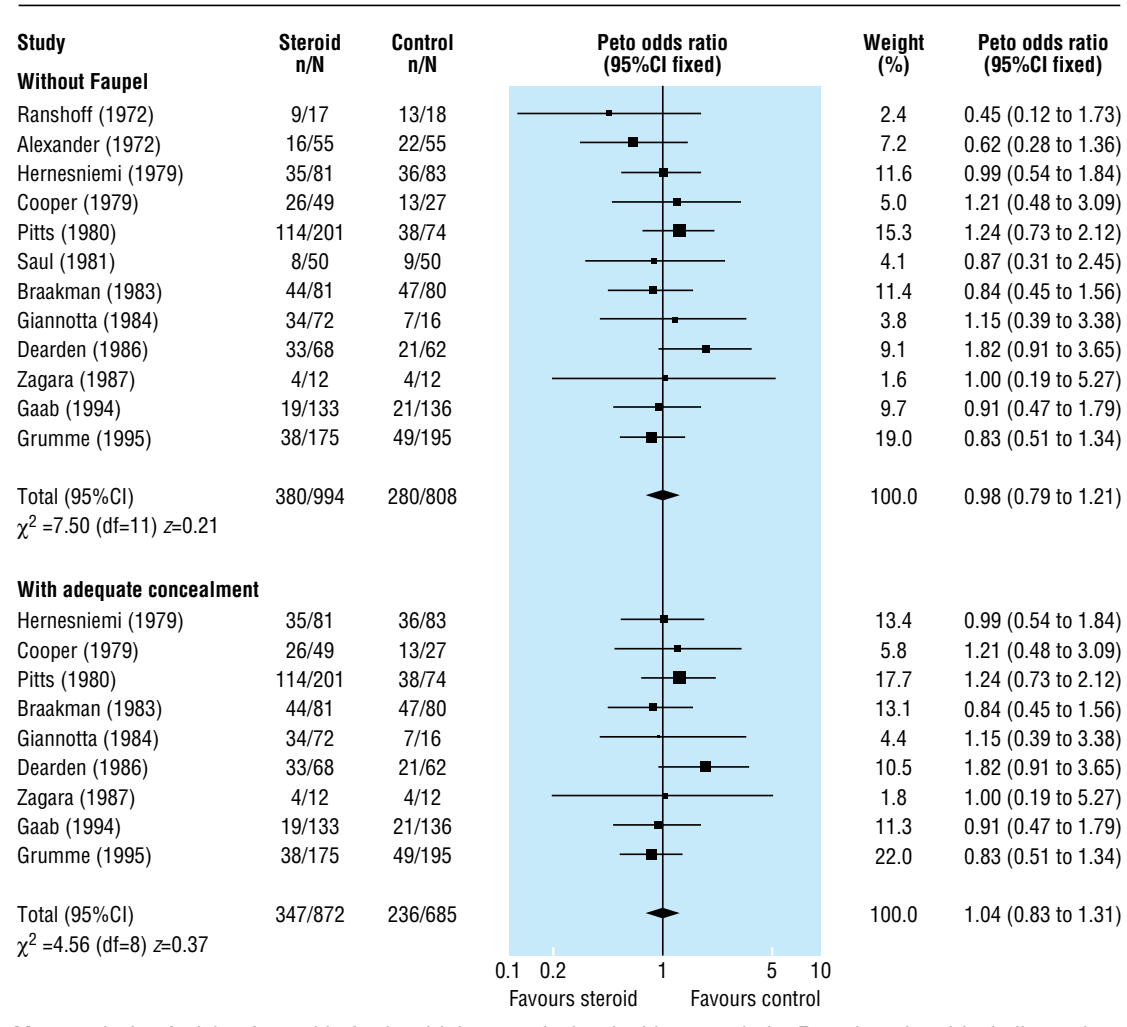

Meta-analysis of trials of steroids for head injury recalculated without study by Faupel et al and including only trials with adequate concealment ing for adult onset disorders became feasible.

She is right to distinguish the situation of adolescents requesting testing from that of parental requests relating to young children. Such requests from adolescents are rare and would receive full and sensitive discussion on an individual basis, as she recommends. They often turn out really to be requests for more general information or for recognition of the issue within the family, but it is unlikely that a request for testing would be ruled out purely on grounds of age.

The 1996 paper of Binedell et $\mathrm{al}^{2}{ }^{2}$ to which Dickenson does not refer, explored the issue of adolescent requests for tests for Huntington's disease in detail and came to the same conclusion that an individual assessment based approach was desirable. This paper, with the subsequent widespread discussion at British and European genetics meetings, contributed to the evolution of practice and policies from the more rigid original guidelines. These guidelines were, as Dickenson states, framed more with young children in mind. Such evolution of practice is important and inevitable in a new discipline. This current, more individualised, approach to requests from adolescents requesting genetic tests is reflected in the 1998 recommendations of the UK health departments' advisory committee on genetic testing (also not referred to). ${ }^{3}$

If the author had been in touch more closely with clinical genetics units across Britain she would have found a large measure of agreement with many of the points she makes. She would also have discovered that this topic has been under widespread discussion, with consequent modification of practice, for several years. Perhaps the general lesson to be learnt is that the important contributions from ethicists and other social scientists are most valuable when they are able to work closely with geneticists and other professionals in studying the difficult problems that new developments in genetics raise.

Peter S Harper consultant in medical genetics

Ruth Glew clinical nurse specialist

Ruth Harper clinical assistant in medical genetics

Institute of Medical Genetics, Heath Park, Cardiff

1 Dickenson DL. Can children and young people consent to be tested for adult onset genetic disorders? BMJ 1999;318:1063-6. (17 April.)

2 Binedell J, Solden JR, Scourfield J, Harper PS. Huntington's disease predictive testing: the case for an assessment approach to requests from adolescents. I Med Genet 1996:33:912-5.

3 Advisory Committee on Genetic Testing. Report on genetic testing for late onset disorders. London: Department of Health, 1998.

\section{Genealogy certainly matters for} multifactorial genetic disease

EDITOR-We have some difficulties understanding Edwards's letter about the genetic mapping in Iceland. ${ }^{1}$ His first paragraph suggested that it was not about ethical or political issues, but the last paragraph was. His collaborations with some of our local critics who have been doing research on the genetics of schizophrenia may explain this. 
What is clear, however, is that Edwards takes the rather narrow view that genealogical information is useful only for diseases that can be fitted with unifactorial models. We disagree. Data are the fuel of all scientific investigations, and in the case of genetic studies it is intuitively obvious that phenotypic, genetic, and genealogical data are all relevant. All methods for finding susceptibility genes with anonymous markers (even those that do not assume unifactorial aetiology) involve searching for genomic regions that patients share.

Apart from power considerations, one aspect that distinguishes the various approaches is resolution. For linkage and family studies a low density of markers is necessary to find sharing, but it results in low resolution. Association techniques studies that focus on unrelated, or distantly related, affected individuals can provide very fine resolution, but a high density of markers is required to capture the sharing.

Given our genealogy, at any stage of the gene mapping effort we have the flexibility to study affected relatives separated by any distance desirable and match it with the marker density required for that distance. We can perform studies that are half way between traditional family studies and association studies and avoid having to jump directly from one extreme to the other. Our extensive genealogy database allows us to fractionate the patient material, perhaps making the genetic basis for the disease in this subgroup even simpler.

The proposed Icelandic Healthcare Database would anonymise and combine such data for a large proportion of the population (those who give active informed consent for the genetic data to be used), ${ }^{2}$ allowing one to ask fundamental questions about how interactions among genes, or between genes and the environment, cause disease.

Mapping genes for common disorders is not easy, and combining extensive genealogy of an isolated population with powerful genome sharing methods represents a new approach to human genetics. But this may be irrelevant to Edwards, who seems to have contempt for most state of the art techniques.

Augustine Kong director of statistical genetic Jeff Gulcher vice president of research and development

Kari Stefansson chief executive officer

Decode Genetics, Lynghals 1, Reykjavik, Iceland 110 jgulcher@decode.is (Augustine Kong)

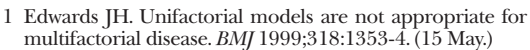
2 www.database.is (accessed 20 August 1999).

\section{Researchers got it right in estimating numbers of doctors lost from NHS}

EDITOR-Hall questions the independence of the two methods we used to identify doctors working in the NHS and therefore questions the results obtained by our use of capture-recapture analysis. ${ }^{2} \mathrm{He}$ assumes that both methods depend on doctors' propensity to respond to inquiries. They do not.

We identified doctors working in the NHS by using two fundamentally differen approaches. In both cases, the starting point was the nominal list of all doctors who qualified in Great Britain in 1988.

The first approach used the questionnaires of the Medical Careers Research Group sent to all qualifiers regardless of where they were by 1995 (the year of the survey). The information obtained about doctors' employment in the NHS depended on the doctors' responses. The second approach used the Department of Health's records, analysed by the department for the same doctors at the same point in time. These records are based on information supplied to the department by all NHS trusts, generally from their payroll and personnel records; the information is not based on any inquiry to doctors but on whether the trust held an NHS contract for the doctor at the relevant time. It is the combination of results from these two independent methods that gives strength to our figure of an $83 \%$ participation rate in the NHS

Even if the two methods were not statistically independent, Hall's point is flawed. He assumes that doctors identified as working in the NHS by one method would be more likely to be identified as working in the NHS by the other method. If true this would reduce the estimated total number working in the NHS rather than increase it. In calculating the capture-recapture estimates, the higher the overlap between those identified by both methods, the smaller the estimated additional number not identified by either method. Thus the real participation rate would be a little lower, not higher, than that with which Hall takes issue.

Michael Goldacre unit director

Trevor Lambert statistician

trevor.lambert@dphpc.ox.ac.uk

UK Medical Careers Research Group, Oxford

University, Oxford OX3 7LF

1 Hall GH. Authors may have underestimated number of young doctors still working in NHS. BMJ 1999;318:1486. young doctor .)

2 Lambert TW, Goldacre MJ. Career destinations seven year on among doctors who qualified in the United Kingdom in 1988: postal questionnaires survey. BMJ 1998;317:1429-31.

\section{Bilateral cataract extraction can be safely done within 48 hours}

EDITOR-Gray et al highlighted the benefit of bilateral cataract surgery, particularly if the second eye is operated on within six weeks of the first. ${ }^{1}$

We agree with their view that surgery should be directed at those with most need. Nevertheless, Gray et al also recognise that an increase in the availability of cataract surgery would help to satisfy increased demand. A step towards achieving this and accomplishing surgery in both eyes is simultaneous bilateral cataract extraction. Although this does not greatly reduce operating time, it halves the number of outpatient visits required. However, simultaneous bilateral extraction is controversial, as shown when the issue was raised in the Journal of Cataract and Refractive Surgery in $1997 . .^{3}$

Most conservative surgeons agree that simultaneous extraction is appropriate only in unusual circumstances-for example, when the surgery requires general anaesthesia and repeated general anaesthesia represents a risk to the patient. The principal concern which prevents many surgeons adopting simultaneous extraction is the risk of potentially blinding bilateral postoperative infection: endophthalmitis.

A study of 316 cases of simultaneous bilateral extraction indicated a low incidence of complications, and although endophthalmitis occurred in one case, it was unilateral. ${ }^{4}$ Despite this, most cataract extractions in the United Kingdom are performed on one eye at a time with a gap of many weeks or months until the second eye receives surgery. Endophthalmitis has a low incidence, estimated as $0.1 \%$, and, although it may occur at any stage after surgery, serious infection with pathogenic bacteria usually occurs within 48 hours.

A further concern about simultaneous extraction is the inability to alter the choice of power of intraocular lens placed in the second eye based on experience with the first. Our eye department offers patients presenting with bilateral cataracts surgery on one eye at a time but on consecutive operating lists 48 hours apart. We feel that this avoids or reduces the perceived risks and problems of simultaneous extraction. At the same time it achieves the benefits of halving outpatient visits and performing surgery on both eyes in close succession. To date, we have not experienced any cases of endophthalmitis in this group of patients.

Adam Booth senior house officer in ophthalmology Andrew Coombes specialist registrar in ophthalmology

andrewcoombes@compuserve.com

Chad Rostron consultant ophthalmologist

Department of Ophthalmology, St Georges

Hospital, London SW17 0QT

1 Gray CS, Crabtree HL, O'Connell JE, Allen ED. Waiting in the dark: cataract surgery in older people. BMJ 1999:318:1367-8. (22 May)

2 Masket S, ed. Consultation section.J Cataract Refract Surg 1997;23:1437-41.

3 Responses to Consultation section (letters). J Cataract Refract Surg 1998;24:430-1.

4 Beatty S, Aggarwal RK, David DB, Guarro M, Jones H, Pearce JL. Bilateral simultaneous cataract surgery in the UK. BrJ Ophthalmol 1995;79:111-4.

5 Kressloff MS, Castellarin AA, Zarbin MA. Endophthalmitis Surv Ophthalmol 1998;43:193-224.

\section{Pleasing both authors and readers}

\section{From ELPS to hypER papers}

EDitor-The idea of introducing a dual publishing strategy-a short version in the paper journal and a longer version in the electronic journal ${ }^{1}$-is a move in the right direction, but in its present form at the $B M J$ new problems arise. How should these different versions be cited or indexed? Which sections of the long paper should be deleted for the abridged version? Will there 
be multiple electronic versions of a single paper aimed at different readerships? Does this all really save time, or will readers eventually have to browse through two or more versions of the same paper to find the information they are looking for?

Rather than publishing simultaneously two or more "linear" versions of the same paper I suggest going one step further and using the full power of the medium of the world wide web with hypertext to enrich a short paper (hypertext enriched research papers, or hypER papers). The short hypER paper could be printed in the paper journal and in the same form be published electronically as hypertext-that is, containing "clickable" phrases enabling readers to "zoom" to the aspects of the paper that they are specifically interested in. The discussion could, for example, contain hyperlinked phrases such as "owing to methodological problems, data on quality of life may be biased towards underestimation of the drug effect," which may be skipped by general practitioners and clicked by researchers interested in this methodological issue. This would prevent readers interested in specific details from having to read through a second longer version, and for indexing or citation purposes it avoids having to deal with multiple parallel versions of an article.

The next step would be to automatically display articles customised to the needs of individual readers. The system would know the preferences and background of registered readers (perhaps even by learning from previous actions) and expand automatically the hyperlinks that show potentially interesting information for a particular reader-for example, molecular details for a molecular biologist and additional explanations for a general practitioner.

However, this all clearly means more work for editorial staff, so you may end up pleasing authors and readers but not editors.

Gunther Eysenbach editor,Journal of Medical Internet Research

Unit for Cybermedicine, Department of Clinical Social Medicine, University of Heidelberg, Bergheimer Strasse 58, 69115 Heidelberg, Germany ey@yi.com

I Delamothe T, Mullner M, Smith R. Pleasing both authors and readers. BMJ 1999;318:888-9. (3 April.)

\section{Summary of electronic responses}

We received 11 electronic responses ${ }^{1}$ to our proposal to publish shortened versions of articles in the paper version of the $B M J$ and longer versions in the $e B M J$ (ELPS, as we call it, for "electronic long, paper short."). ${ }^{2}$ In general the response was positive.

"ELPS is a relevant innovation and its 'evolution' should be encouraged ... new proposals such as ELPS could really contribute to merge useful scientific experiences from a wide range of professions; it could foster interactions 'between' the worlds of research and practice" (F Carinci).

"Instead of making the paper journal a repetition of the $e B M J$, it is indeed a novel experiment to produce shortened versions for reading between patients in the surgery and have the full text, even full data, available online for the more seriously interested academics or researchers. Web publishing is the present not the future" (I Chakravorty).

Some readers, however, prefer to have everything in the paper version because they are "highly interested in knowing all the available information when an article is published. Jumping to conclusions from some few lines is a common mistake among many professionals" (R Pflaumer). "The difficulty will be how to shorten the articles and where to place the weight and emphasis of the study." (A Risk).

Cautious voices remind us: "If the point of ELPS is to shrink work so that more articles of general interest can be published, then the $B M J$ must ensure that 'cyberwork' receives the same degree of recognition as work in the original journal" (A Rashid). J O'Keefe worries that "the fruits of [the authors'] labour will ... disappear into cyberspace within a couple of years." eBMJ 1999.318. Pleasing both authors and readers. 7188/888\#responses (accessed 5 August 1999).

2 Delamothe T, Müllner M, Smith R. Pleasing both authors and readers. BMJ 1999;318:888-9. (3 April.)

\section{Editors' reply}

Although the response to our editorial was generally positive, research among readers shows that many are wary of ELPS. Nevertheless, we think that the arguments for proceeding with the experiment are strong. Our hope, even expectation, is that both readers and authors will like ELPS once they get used to it. We plan to continue experimenting with different ways of shortening articles for the paper version of the journal, and we have thought of about seven different ways of doing so, some extreme some moderate. We may well include examples of all the different methods in a future edition of the journal. The shorter versions are identifiable both on the website and in the paper journal by the inclusion of the term (abridged) at the end of the citation.

Tony Delamothe web editor

Marcus Müllner editorial registrar

Richard Smith editor

$B M J$

\section{Structuring the discussion of scientific papers}

\section{Results of single studies must be assessed} in context of relevant systematic reviews

EDITOR-Docherty and Smith invite comments on their proposal to structure the discussion section of original scientific papers. ${ }^{1}$ The proposal, although not new, does not go far enough to address the quality problems of contemporary published research.

The key element that is missing from the proposal is the explicit insistence that "reports of primary research should begin by referring, in the introduction, to the results of a systematically conducted, published review of the results of relevant previously reported studies, explaining why the current study was justified. The discussion section of the report should set the data generated by the new study in the context of all the evidence available at the time of analysis."

That proposal, made by Chalmers back in 1991, should be explicitly incorporated in Docherty and Smith's proposal. The main obstacle to such an approach so far has been the existing tension between the need for publishing sound science and the business survival of most journals, which depend on a steady stream of papers to continue operating. Old habits die hard. Clarke and Chalmers found little evidence that journals adequately implemented CONSORT recommendations that results of randomised controlled trials should be discussed in the light of all available evidence. ${ }^{3}$ Colleagues and I found editorial change equally difficult to achieve in the field of economic evaluation. $^{4}$

It is no longer acceptable for authors to publish research that may have an impact on people's lives without attempting to interpret the results within the available body of systematically collected and evaluated knowledge. Studies that are likely to have a major impact on the way that health care is delivered and financed should be editorially peer reviewed by being compared with their "peer studies" in terms of methods, topic, or results.

The absence of a systematic review on a topic (which is becoming less likely, as the methods and uses of systematic reviews become accepted) is not an excuse for presenting information from a single study without making any reference to its peer studies. As Docherty and Smith point out, the practice of making such a reference should help minimise bias in discussion sections.

Tom Jefferson coordinator Cochrane Vaccines Field, UK Cochrane Centre, Surrey GU16 6JP

toj1@aol.com

1 Docherty M, Smith R. The case for structuring the discussion of scientific papers. BMJ 1999;318:1224-5. (8 May)

2 Chalmers I. Improving the quality and dissemination of reviews of clinical research. In: Lock SP, ed. The future of medical journals: in commemoration of 150 years of the British medical yournals. in commemoration of 150 years of the Britist

Medical Journal.London: Buy Publishing Group, 14

3 Clarke M, Chalmers I. Discussion sections in reports of controlled trials published in general medical journals. Islands in search of continents? JAMA 1998;280:280-2.

4 Jefferson TO, Drummond MF, Smith R, Yi Y, Pratt M, Kale R. Evaluating the BMJ guidelines on economic submissions-prospective audit of economic submissions to the BMJ and Lancet.JAMA 1998;280:275-7.

5 Jefferson TO, Deeks JJ. The use of systematic reviews for peer-reviewing. A population approach. In: Godlee F, Jefferson TO, eds. Peer reviews in biomedical science. London: BMJ Books (in press).

Wouldn't structured discussions be taking things too far?

EDITOR

Background I write to congratulate Docherty and Smith on their editorial on structured discussions in scientific papers.

Methods However, they may not have gone far enough.

Results Why not have structured editorials and structured news items, book reviews, fillers, and personal views? 
Discussion Even letters would be much more entertaining to the scientific reader if rigidly structured.

John R Petrie clinical lecturer

Department of Medicine and Therapeutics,

Western Infirmary, Glasgow G11 6NT

jrp1s@clinmed.gla.ac.uk

I Docherty M, Smith R. The case for structuring the discussion of scientific papers. BMJ 1999;318:1224-5. (8 May.)

\section{Randomised controlled trial of structured discussions is needed}

EDITOR-Docherty and Smith's proposal that the discussion of scientific papers should be structured is a good one. ${ }^{1}$ As in clinical research, the need for an evidence base in the editorial process is essential. The proposal makes sense, but a randomised controlled trial (like some on editorial process published in JAMA's peer review theme issue last year') is probably the best way of confirming this. This is an ideal occasion for the $B M J$ to conduct such a trial.

Aldemar Araujo Castro visiting assistant professor Division of Internal Medicine, Universidade Federal de São Paulo, São Paulo, Brazil

aldemar.dcir@epm.br

Competing interests: Professor Castro is deputy editor of São Paulo Medical Journal.

1 Docherty M, Smith R. The case for structuring the discussion of scientific papers. BMJ 1999;318:1224-5. (8 May.) 2 JAMA 1998;280:203-306. [Peer review theme issue.]

\section{Effect of screening on cervical cancer mortality in England and Wales}

\section{Interactive effects and causation must be considered}

EDITOR-From their modelling of mortality data Sasieni and Adams estimated the number of deaths from cervical cancer prevented as a result of screening. ${ }^{1}$ Two issues must be considered.

Firstly, they did not consider possible interactive effects between the age effect and the cohort effect. Factors such as increases in life expectancy, possible improvements in the treatment of cervical cancer, and different secular changes in sexual behaviour among different age groups could all have produced such interactive effects. The authors have not explained why they ignored this possibility.

Secondly, even if there were a reduction of deaths from cervical cancer, it could have been due to reasons other than screening. Furthermore, it may be too soon to expect a large effect on mortality data in 1997 from screening carried out between 1988 and 1995.

Wai-Ching Leung senior registrar in public health medicine

Northern Region Public Health Medicine Training Scheme, County Durham Health Authority,

Durham DH1 5XZ

Wai_chingleung@hotmail.com

1 Sasieni P, Adams J. Effect of screening on cervical cancer mortality in England and Wales: analysis of trends with an age period cohort model. BMJ 1999;318:1244-5. (8 May.)

\section{Author's reply}

EDITOR-We agree that a reduction in deaths from cervical cancer need not be due to screening and that interactions should be considered. A multiplicative model of age and cohort effects fits the data between 1950 and 1987 reasonably well. Additional terms (interactions) are needed to obtain a good fit to more recent data. The trends in year of death in each of four age groups that we presented are interactions between age and cohort (year of birth). As our graphs showed, there is little evidence of an interaction before the 1980s but substantial evidence (particularly in younger women) since 1990.

Increased life expectancy would not affect age specific rates of cervical cancer. There was little improvement in treatment of invasive cancer from the 1950s until the benefit of concurrent chemotherapy and radiotherapy was shown earlier this year.

The appropriateness of the age and cohort effects model until the mid-1980s suggests that risk is determined at a fairly young age (35 years, say). That is in keeping with the causative role of persistent infection with certain types of human papillomavirus and the observed age specific prevalence of infection with human papillomavirus. ${ }^{2}$

It seems unlikely that changes in sexual behaviour could account for a $60 \%$ fall in mortality from cervical cancer (relative to that expected on the basis of age and birth cohort) since 1987 in women aged 20-54 The long interval from infection with human papillomavirus to death from cervical cancer suggests that changes in sexual behaviour would have had to take place in the 1970s. This excludes the explanation of an effect of publicity for safer sex because of AIDS in the mid-1980s. Among heterosexual women the impact of this publicity was primarily in those under 35 and is more likely to be seen as a cohort effect than as a secular trend.

Papanicolaou screening should affect mortality from cervical cancer for at least 15 years, but some effect might be seen within three years. Screening leads to the detection and treatment of both occult invasive cancers in previously unscreened women and precancerous lesions. The former could result in death within three years if untreated. Hence screening carried out since 1988 is most likely to have affected mortality since 1991, with earlier trends being attributable to less well organised screening in 1970-87.

As we said in our paper, "Although it is dangerous to attribute calendar effects to cervical screening, we know of no better explanation."

\section{Peter D Sasieni senior scientist}

Department of Mathematics, Statistics, and

Epidemiology, Imperial Cancer Research Fund, London WC2A 3PX p.sasieni@icrf.icnet.uk

1 National Cancer Institute. Concurrent chemoradiation for cervical cancer. Clinical announcement. Washington, DC: NCI, 1999.

2 International Agency for Research on Cancer. IARC monographs on the evaluation of carcinogenic risks to humans. Vol. 64. Human papillomaviruses. Lyons: IARC, 1995.
Having advanced resuscitation facilities at end of marathons does not guarantee survival

Editor-I feel great sympathy for the parents of Anna Loyley, who died suddenly after finishing the Bath marathon. ${ }^{1}$ The details are unclear, but it seems to be accepted that her sudden cardiac death might have been avoided through appropriate use of the (available) automatic external defibrillator. Nevertheless, the scapegoating of the doctors (and presumably the St John Ambulance workers) involved in the case is depressing. ${ }^{2}$ The parents' campaign to have advanced resuscitation facilities, paramedics, and doctors at all marathons held outside a stadium may be logical in relation to this case but is otherwise Utopian.

Given the 26 miles of a marathon course and the numbers usually involved, runners are unlikely ever to be comprehensively protected. Most sudden sporting deaths result from ischaemic heart disease, complex cardiac conduction disorders, or cardiomyopathy, which may be resistant to conventional resuscitation. ${ }^{3}$ Even in apparently ideal circumstances (for example, witnessed cardiac arrest in a large emergency department) survival rates may be less than $50 \%{ }^{4}$

It is far from clear that deploying doctors and equipment at the finishing lines of races would achieve the inevitable survival that the Loyleys' campaign implies. In reality, if anything should be done to prevent sudden sporting deaths it is to ban participants with the vaguest history of giddiness, breathlessness, or angina related to exercise. Tragically, this is often obvious in retrospect.

Sophisticated cardiological screening or deployment of advanced resuscitation teams might or might not diminish the risks of running, but some risk is inescapable in all human enterprise and the cost-benefit ratio involved must be assessed realistically. The benefits to society of sporting and other events are great. People seeking to eliminate risk should recognise that they may also eliminate the amateurism and altruism that are in such short supply in our society.

L C Luke consultant in accident and emergency medicine

Royal Liverpool University Hospital, Liverpool L7 8XP

Competing interests: Dr Luke has been involved in accident and health hazard prevention at venues out of hospital in Liverpool and in miscellaneous preventive exercises.

1 Loyley P, Loyley P. Medical rules are needed in marathons in the United Kingdom. BMJ 1999;318:1285-6. (8 May.) 2 Dyer C. "Good Samaritans" face grilling. BMJ 1998;317:1100.

3 Whittington RM, Banerjee A. Sport-related sudden natural death in the city of Birmingham.J R Soc Med 1994;87:18-21.

4 White SP, Guly HR. Survival from cardiac arrest in an accident and emergency department: use as a performance indicator? Resuscitation 1999;40:97-102.

\section{Rapid responses} $e \mathrm{BM}$

Correspondence submitted electronically is available on our website www.bmj.com 